\title{
Correction to: Impact of Laparoscopic Sleeve Gastrectomy on Gut Permeability in Morbidly Obese Subjects
}

\author{
Teresa Kellerer $^{1} \cdot$ Beate Brandl $^{2} \cdot$ Janine Büttner ${ }^{3} \cdot$ Ilias Lagkouvardos ${ }^{4} \cdot$ Hans Hauner $^{1,5} \cdot$ Thomas Skurk $^{1,2}$
}

Published online: 29 April 2021

(C) Springer Science+Business Media, LLC, part of Springer Nature 2021

\section{Correction to: Obesity Surgery (2019) 29:2132-2143 https://doi.org/10.1007/s11695-019-03815-6}

In the original article there is a typing error in Table 1. It was reported that body weight $(\mathrm{kg})$ of obese patients before surgery (LSG V1) is $\mathbf{1 2 5 . 0}(133.9 ; 175.7)$. It should read $\mathbf{1 5 2 . 0}$ (133.9; 175.7).

Publisher's Note Springer Nature remains neutral with regard to jurisdictional claims in published maps and institutional affiliations.

The online version of the original article can be found at https://doi.org/ 10.1007/s11695-019-03815-6

\footnotetext{
Thomas Skurk

skurk@tum.de

Teresa Kellerer

teresa.kellerer@tum.de

Beate Brandl

beate.brand1@tum.de

Janine Büttner

janine.buettner@charite.de

Ilias Lagkouvardos

ilias.lagkouvardos@tum.de

Hans Hauner

hans.hauner@tum.de
}

1 Else Kröner-Fresenius-Center of Nutritional Medicine, Technical University of Munich, Freising, Germany

2 ZIEL Institute for Food and Health, Core Facility Human Studies, Technical University of Munich, Freising, Germany

3 Charité-Universitätsmedizin Berlin, Medical Department, Division of Hepatology and Gastroenterology, Berlin, Germany

4 ZIEL Institute for Food and Health, Core Facility Microbiome/NGS, Technical University of Munich, Freising, Germany

5 Institute of Nutritional Medicine, Klinikum rechts der Isar, Technical University of Munich, Munich, Germany 